\title{
Presença da história pública em comunidades locais: políticas culturais e exercício de cidadania no contexto de repertórios de ação coletiva - a experiência recente do Centro de Memória de Hortolândia - Prof. Leovigildo Duarte Júnior
}

\begin{abstract}
Presence of public history in local communities: cultural policies and exercise of citizenship in the context of collective action repertoires - the recent experience of Centro de Memória de Hortolândia - Prof. Leovigildo Duarte Júnior
\end{abstract}

\section{Gustavo Esteves Lopes}

Historiador, mestre em História Social (USP), agente cultural concursado da Prefeitura Municipal de Hortolândia, pesquisador do Centro de Memória de Hortolândia, pesquisador do Núcleo de Estudos em História Oral (NEHO-USP) [ $\left.{ }^{1}\right]$

\section{Resumo}

O presente artigo tem o escopo de apresentar conceitos e informes acerca da presença da história pública em comunidades locais, com ênfase em projetos balizados por procedimentos em história oral. O estabelecimento do diálogo entre história pública, história local e história oral, enquanto searas do conhecimento, pode de fornecer, a comunidades interessadas na tessitura de seus laços identitários, subsídios elementares para a elaboração de projetos e ações socioculturais e políticas públicas culturais pautadas pelo exercício de cidadania. No sentido de apontar o desenvolvimento prático destes aportes conceituais acima elencados, são também arroladas algumas experiências recentes do "Centro de Memória de Hortolândia - Prof. Leovigildo Duarte Júnior", nas quais a colaboração entre comunidades, agentes culturais e pesquisadores se apresenta como um estímulo para a construção de repertórios de ação cultural coletiva, local e regional.

Palavras-Chave: 1- História Pública; 2- História Local; 3- História Oral.

\section{Abstract}

This article is intended to introduce concepts and relationships on the presence of public history into local communities, with clear emphasis on procedures for oral history projects. The creation of a dialogue between public history, local history and oral history, as paths of knowledge, can provide, to the concerned communities into the texture of their links to identity, elementary subsidies for the development of projects and socio-cultural activities, as well as cultural public policies guided from the exercise of citizenship. To emphasize the practical development of these conceptual contributions above, some recent experiences of "Centro de Memória de Hortolândia - Prof. Leovigildo Duarte Júnior" are also discuted, in which a close collaboration of communities, researchers and cultural workers is presented as a stimulus for the construction of repertoires of cultural collective action, in local and regional levels.

Keywords: 1- Public History; 2- Local History; 3- Oral History.

1 Todas as citações apresentadas no corpo do texto, cujos originais foram publicados em idioma estrangeiro e não possuem edição nacional, receberam livre tradução do presente autor. 
Argumentar acerca da presença da história pública em comunidades locais significa pautar sua influência, participação e sua vitalidade junto a grupos sociais/étnicos específicos, grupos detentores/produtores de referências/bens culturais e, de modo abrangente, populações, povoamentos circunscritos a bairros e distritos em um município, ou em qualquer esfera de um ou mais Estados-nação. Em uma perspectiva sociocultural, a palavra "comunidade", como afirma Zigmunt Bauman, sugere sempre uma "coisa boa", mas que "evoca tudo aquilo de que sentimos falta e de que precisamos para viver seguros e confiantes" (2003:7-9). E a história pública pode muito contribuir para esta sensação de bem-estar em comunidades, desde que inserida em um contexto de ação coletiva amplo.

As diversas modalidades de produção sociocultural conhecidas no bojo do que se compreende por história pública são, há tempos, veículos de devolução do conhecimento histórico-cultural dos mais eficazes para se atingir o maior número possível de leitores, telespectadores e consumidores em geral sobre os fatos e personagens marcantes, memoráveis, célebres, considerados preponderantes, por exemplo, na evolução político-administrativa de uma localidade; na valoração da trajetória genealógica de um grupo familial/consanguíneo; na representação formal de movimentos/grupos sociais/étnicos e de gênero que reivindicam reparações históricas/sociais/econômicas; e na busca pela salvaguarda de saberes e fazeres próprios/apropriados por indivíduos/mestres/grupos/comunidades.

Por assim dizer, nos primórdios da estruturação profissional da história pública, ocorrida à costa oeste estadunidense (inicialmente à University of California in Santa Barbara), partir de meados da década de 1970, o escopo de conceituar história pública e campos do conhecimento correlatos era motivado pelo uso não acadêmico de ferramentas empregadas no ofício do historiador encastelado em cátedras. Estas ferramentas, porém, poderiam ser muito úteis aos afazeres culturais então relegados à condição de minor histories, sejam estas histórias locais, ou de empresas, grupos étnicos/sociais específicos, narrativas biográficas, sejam estas subsídios para construção de políticas públicas. A revista The Public Historian, em atividade desde 1978, por sua vez, promovida pela referida universidade e financiada pela Rockfeller Fundation, teve como um de seus principais porta-vozes e formadores de opinião o historiador Robert Kelley (1925-1993), que no primeiro volume da referida revista elucidara acerca de sua definição de história pública:

Em seu sentido mais simples, a história pública se refere ao emprego de historiadores e do método histórico fora da academia: no governo, em empresas privadas, nos meios de comunicação, em sociedades históricas e museus, mesmo em situação de prática privada. Historiadores públicos estão em atividade, sempre que, em sua vida profissional, eles são parte do processo público. [Para que serve o historiador público]: Uma questão precisa ser resolvida; uma política pública, elaborada; a utilização de um recurso ou direção sobre uma demanda, planejada de forma mais eficaz; e um historiador é chamado a trazê-la na dimensão do tempo: isto é História Pública. (Kelley, 1978:16)

O campo da história pública, enquanto projeto e produção sociocultural, dentro e além de suas definições latu sensu, compreende produções que vão da criação de museus comerciais/pedagógicos/populares; de exposições fotográficas, e de artes plásticas e visuais, que apresentam paisagens urbanas/rurais (e rururbanas), enfatizando a correlação entre a urbe, a natureza e sua gente; de documentários artísticos/jornalísticos que promovem as diversidades intrínsecas aos movimentos/grupos sociais/étnicos específicos acima descritos, além de tantos outros; a de livros de história social, de memórias biográficas e/ou coletivas, e de crônicas e poesias que descrevem sentimentos de pertencimento e identidade (e seus inversos) de autores que se posicionam como porta-vozes de seus grupos e comunidades. Para Dolores Hayden, dentro deste campo há muitas perspectivas de conteúdo e de público interessado e beneficiário dessas produções culturais; mas para produzir o que ela entende por história de paisagens urbanas (porque historiadora, e arquiteta/urbanista), bem como outros modelos de história local, a história pública de organizações baseadas em comunidades é uma natural aliada deste modo de produzir conhecimento. E a autora afirma que

A grande força desta abordagem à história pública é o seu desejo de uma "autoridade compartilhada" (...) ou uma "história dialógica" (...) que dá poder para que as comunidades definam seus próprios passados. Esta abordagem se baseia no entendimento de que a história de trabalhadores, mulheres, grupos étnicos e de pobres requer variadas matérias-primas, incluindo histórias orais, porque muitas vezes as pessoas, ao invés dos [historadores] profissionais, são as maiores autoridades sobre seus próprios passados. $\mathrm{Na}$ busca por novos materiais, incluindo histórias orais, muitos 
historiadores profissionais treinados tem visto como comunidades puderam definir suas próprias histórias econômicas e sociais. (...) Alguns [desses historiadores profissionais] têm o interesse na capacitação comunitária [ou empoderamento] e vincular à história pública outros modos de organização comunitária. (Hayden, 1997:48-9)

Compreendendo a presença da história pública em comunidades como projeto e produção sociocultural na qual é preponderante o entendimento de sua dimensão territorial, a modalidade história local é, sem dúvida, uma das mais vivazes, porque das mais democraticamente praticadas. Produção que independente de rigores historigráficos emanados de discussões em procedimentos metológicos e aportes conceituais ditos acadêmicos, a história local se fundamenta mais em critérios socialmente estabelecidos dentro das variadas comunidades, como o narrar valorando a diversidade étnica, cultural, e de classe social, e mesmo fatos e personagens memoráveis para o cotidiano destas. A anuência sobre o valor histórico-cultural de uma iniciativa em história local é referendada pela comunidade tornada objeto de pesquisa, ao mesmo tempo em que é sua principal consumidora e beneficiária direta no mais das vezes. A preocupação dos consumidores dessas histórias públicas em comunidades locais reside em interesses e argumentos dos quais o pesquisador profissional deve ter a sensibilidade de não desmerecê-los ou dar maior ênfase ao método de construção historiográfica e de análise, sobretudo se há o contato direto deste junto a membros de comunidades locais.

Ainda que influenciada, ou afetada, por grandes conceitos filosóficos, sociológicos e antropológicos, urbanísticos e economicistas, e historiográficos de toda sorte, um projeto e produção sociocultural em história pública local que se esqueça, por exemplo, de aspectos irrefutáveis dos bens/referências culturais de uma comunidade; que desmereça, ou faça pouco caso, de histórias de vida, hipoteticamente, como a do seu João, da dona Maria, supostos ícones morais daquela comunidade - porque capitulos de bistória indeléveis para aquela gente - pode ser útil a todo restante da humanidade afeita ao tema, mas para a comunidade local em questão, objeto de pesquisa e análise, esta tem a possibilidade de se tornar uma produção sociocultural abstrata, inócua, porque carente de anuência e vivacidade. Além disto, promover a devolução pública da pesquisa ou produção sociocultural sem anuência prévia das comunidades locais; e, por exemplo, desmitificar líderes locais comunitários/políticos de quaisquer matizes ideológicos, culturais e/ou religiosos, de modo a causar certos constrangimentos públicos; acusar indiscriminadamente mazelas sociais e políticas que atinjam parte ou o todo da população, ou povoamento, sem consentimento público, negociação ou autorização prévia; não creditar devidamente a grupos/comunidades detentoras/produtoras a titularidade moral e/ou patrimonial de seus bens/referências culturais identificados e reproduzidos publicamente/comercialmente: eis algumas das condutas que fogem cabalmente do que se pretende de uma história pública em comunidades locais, conforme este campo de trabalho vem se aperfeiçoando ao longo das últimas décadas.

É o que Carol Kammen se refere como uma postura de historiador local que, para realizar seu trabalho, "censura a história", bem como igualmente se "autocesure" (Kammen, 2003:63) - postura esta algo que se pode bem elucidada pelo ditado popular, que vale muito ao pesquisador e a qualquer outra pessoa, sobre "saber por onde e com quem anda". Além de o pesquisador ter que esclarecer de onde, saber de quem e para quem realiza sua história pública e local, é necessário que o mesmo também se apresente às comunidades beneficiárias, e diga de onde se pronuncia, e quais suas intenções, e mesmo quem o financia. Para facilitar o entendimento sobre os limites de atuação possíveis em história local, e sobre como este campo é tomado pelo senso comum, seria interessante apresentar certos apontamentos elucidados pela historiadora acima referida, os quais resumem bem este escopo, sobretudo para quem o recebe:

(...) hoje a história local pertence a todos nós, imigrantes e estabelecidos há muito tempo, pessoas com ancestrais enterrados em cemitérios locais, e recém-chegados. Mas, mesmo com as novas inclusões, há temas que ainda são geralmente evitados por sociedades [associações, etc.] de história local. E isso, por si só nos diz algo interessante. Poucas sociedades histórias locais ou historiadores locais encaram este desafio. A história local é geralmente considerada pela maioria das pessoas como uma forma de construção de uma comunidade, uma forma de "boom" da prosperidade local, para promover a sua história, e para unir as pessoas em torno de um passado comum, ou uma maneira de entender o próprio lugar. (Idem: 68)

Por mais que a tarefa de pesquisadores profissionas de história pública em comunidades locais também dependa de um arcabouço conceitual e metodológico para viabilizar projetos e planos de produções 
documental e analítica, este não é o interesse prioritário para as próprias comunidades locais atendidas; pois os interesses, de fato, estão mais voltados para como se dão as inter-relações pessoais entre pesquisadores e colaboradores, de forma que sejam prevalecidas as normas de conduta interna aos diversos grupos inseridos em comunidades locais, ainda que posturas que sempre prezem por equanimidade e isonomia jamais devam ser abandonadas. Postura que caminha para um consenso entre pesquisadores e estudiosos da história pública, no que se refere à possível inter-relação a ser criada junto a comunidades locais é aquela em que o pesquisador profissional busque a inversão da corrente lógica de difusão cultural (de que ele é quem pode levar conhecimento, o saber, ao povo, mesmo na melhores das intenções), e se preocupe em compartilhar e reconhecer autorias e, por conseguinte, "compartilhar e reconbecer autoridades", no sentido de que ambas as partes envolvidas se responsabilizem pela construção de histórias públicas, em suas mais diversas modalidades, utilizando dos procedimentos mais acessíveis a pessoas das mais amplas formações profissionais e níveis de instrução escolar. Michael Frisch compreende, a partir de noções de história oral e pública, e à luz de sua própria experiência profissional, que a autor-idade compartilhada é uma saída para o embate entre a vigente necessidade de historiadores/pesquisadores ampliarem seu campo de atuação e as respostas a legítimas demandas sociais sobre a construção do conhecimento histórico, pois

novas formas de história pública [vem travando] uma espécie de guerra de guerrilhas contra essa noção de autoridade acadêmica profissional: a promessa de história de comunidades, de produções audiovisuais sobre pessoas, de encenações teatrais [bistóricas e socioculturais], de muitas aplicações de história oral tem sido [formas de] empoderamento - [isto e] formas de gerar devolução para comunidades específicas ou que gere a partir de dentro de si a autoridade para explorar e interpretar suas próprias experiências; experiências estas tradicionalmente invisíveis em história formal, porque previsíveis sobre quem e o que é relevante; interpretações estas regularmente ignoradas ou que sofrem resistência por parte do meio acadêmico, em virtude de seu conteúdo político e de [suas conseguintes] implicações. (Frisch, 1990:XXI).

"Autoridade compatilhada" - conceito no qual se engloba uma noção de "autoria compartilhada" - seria, juntamente a de ação cultural e coletiva, pois, alternativa a esta difusão cultural que, na melhor das intenções, seria um "tráfego entre entidades integrais", ou um "tratamento de culturas como totalidades distintas" (Bauman, 1999: 67). Dentre as searas da história pública que mais caminha para superar a noção de difusão cultural pela de autoridade compartilhada, porque ação cultural propriamente dita, e enquanto proponente de projetos e produção sociocultural em comunidades locais, é a história oral (Caunce, 1994). Este campo do conhecimento que por vezes parece uma simples ferramenta de pesquisa em história do tempo presente, em outras um campo disciplinar autônomo, faz da sua fragilidade institucional a anima a-bieráquica que a permite ser empregada em projetos, programas e produções documentais e analíticas delicados, como qualquer destes que sejam implementados junto e para comunidades locais. Se há uma chave que abra as portas para tal capacidade de anuência para sua execução junto a comunidades locais é a autor-idade (author-ity) compartilhada (Frisch, 1990, 2012; Hamilton e Shopes, 2008; Assis, 2011) no proceder de sua execução e da devolução pública.

Ainda que seja doloroso para um pesquisador, por exemplo, abdicar da autoria individual sobre um trabalho que, sem o mesmo, por exemplo, jamais um livro ou um documentário audiovisual existiria enquanto tal, a decisão em partir para o caminho da história pública é uma escolha sem volta. A satisfação do pesquisador que lida com história pública, ao aprender e transmitir conhecimento, e principalmente agregar gente que acredita em suas propostas, tem um preço muito alto: o preço de contribuir para que uma própria comunidade local seja responsável pela tessitura de sua história, pela (re)construção de memérias individuais e coletivas, e muito mais que isto, à medida que a história pública se torne socioculturalmente presente junto à comunidade. Dados estes condicionantes subjetivos que perfazem a tarefa de um pesquisador junto a comunidades, campos do conhecimento como história pública, história local e história oral se tornam indissociáveis, correlatos, intrínsecos.

Buscar a sobreposição da noção de difusão cultural pela autoridade compartilhada, no campo da ação cultural coletiva, na elaboração e na execução de projetos e programas em história pública junto a comunidades locais, empregando procedimentos de história oral, é meio de realizar algo que, se estruturado com anuência e viabilidade econômica, tem condições se tornar perene, vivaz, presente. Por isto que, tão quanto um movimento social, a iniciativa de projetos e produção sociocultural em história pública é uma ação coletiva constituída de repertórios nos quais estão elencadas não somente aspectos relevantes de memórias individuais e coletivas, 
mas reivindicações pertinentes ao tempo presente de comunidades locais. $\mathrm{O}$ ato de produzir documentos e análises historiográficas - permeado à luz da história oral, local e pública, por exemplo - sobre histórias de vida e lugares de memória tem motivos para ocorrer: é voluntária, intencional, forjadas por meio de autoridades compartilhadas, porque negociadas entre as partes.

Ainda que tratar de repertórios de ação coletiva remeta diretamente ao aporte conceitual e ao procedimento metodológico inicialmente desenvolvidos por intelectuais como Charles Tilly (1929-2008), mais uma vez esta forma de entendimento sociohistórico receberá novas interpretações e usos, os quais, contudo, não se distanciam em essência de seu locus epistemológico original. Charles Tilly se referia a repertórios de ação coletiva segundo o conjunto de resultado de pesquisas, lançando mão das mais variadas ferramentas e fontes documentais - em história e quadros sociais comparados - a partir dos quais era possível identificar motivações, desenvolvimento, e transformações ocorridas historicamente com movimentos sociais e políticos, que passaram por contendas e conflitos de toda sorte e escala. Intelectual vocacionado a dizer por metáforas, Tilly assim comparou seu entendimento por repertórios de ação coletiva a uma estrutura organizacional de uma companhia teatral:

\begin{abstract}
Repertórios de ação coletiva não designam performances individuais, mas meios de interação entre parelhas ou um maior conjunto de atores. A companhia, e não um indivíduo, mantém um repertório. [Por exemplo], o mais simples conjunto (digamos, um grupo de trabalhadores) fazendo reivindicações coletivas, e um outro (digamos, o patrão deste grupo de trabalhadores) se tornando o objeto, a causa, daquelas reivindicações. E que o conjunto simples se articule em mais parelhas fazendo reivindicações de uns sobre outros, e em trios, até chegar às matrizes complexas da política nacional. Nem todas as reivindicações coletivas, contudo, envolvem conflito aberto. Os partícipes de celebrações coletivas costumam fazer reivindicações de uns sobre outros, exigindo pouco mais do que uma afirmação compartilhada de identidade; líderes convocam seguidores para apoiá-lo, e seguidores declaram sua solidariedade sem necessariamente despertar conflitos de interesse. (Tilly, 1995: 27)
\end{abstract}

Apercebe-se do excerto acima que, ao conduzir e contextualizar tais definições de repertórios para os campos de histórias pública, oral e local, é possível duplamente utilizá-los: pensar os repertórios não somente como ao modo mais aproximado do que pretendia o próprio Tilly, como objetos de pesquisas históricas aplicadas à formulação de quadros sociais específicos, mas tornar estes campos do conhecimento (bistória pública, história local e história) os próprios repertórios de ação coletiva. Ao elaborar projetos e produções documentais e analíticas nas quais há certa sensação de autoridades compartilhadas entre pesquisadores e comunidades, e reunida esta a outras experiências semelhantes, há condições sociais apropriadas para essas serem reconhecidas como repertórios de ação coletiva em história pública, de história local e de história oral. De certa forma, dada a ampla produção e divulgação de histórias orais, locais e públicas em países como Estados Unidos, Austrália, Grã-Bretanha, dentre outros, pode-se dizer que já existem repertórios de ação coletiva, em construção, próprios à presença destes campos de produção historiográfica e sociocultural amplas, ainda que não necessariamente se definam estritamente nestes termos (Almeida e Rovai, 2011).

Dentre os possíveis repertórios de ação coletiva em história pública, história local e história oral em que são estabelecidas autoridades compartilhadas entre pesquisadores e comunidades são aqueles pautados por estudos e, sobretudo, políticas culturais. Os estudos culturais são capazes de responder a pertinentes demandas sociais, utilizando-se de ferramentas que trazem para o debate público traços de subjetividade emanados de oralidades, saberes, celebrações, formas de expressão, lugares de memória que conferem sentimentos de pertencimento e de identidade (e seus inversos) a comunidades locais; ao passo que sua aplicação às políticas públicas culturais é estratégia básica de envolver indivíduos e grupos detentores/produtores de bens culturais - desde que sinceros representantes de comunidades locais específicas - na própria elaboração de projetos, pesquisas e outras produções que não somente revelem memórias coletivas e histórias de vida e contribuam para uma diversa produção sociocultural, mas que contribuam, igualmente, para a inevitável urgência de geração de renda e emprego - este último, preceito substancial do exercício de cidadania.

Políticas culturais se tornam, pois, campos de interlocução entre pesquisadores e comunidades, uma vez que a motivação para se levar a cabo tais projetos, pesquisas e produções é sensibilizada quando estas envolvem financiamento, com vistas sobretudo à geração de renda e emprego. Na perspectiva da política cultural, enquanto uma "ciência da organização das estruturas culturais", Teixeira Coelho assim a define em seu Dicionário Crítico de Política Cultural: 
(...) a política cultural é entendida habitualmente como programa de intervenções realizadas pelo Estado, instituições civis, entidades privadas ou grupos comunitários com o objetivo de satisfazer as necessidades culturais da população e promover o desenvolvimento de suas representações simbólicas. Sob este entendimento imediato, a política cultural apresenta-se assim como o conjunto de iniciativas, tomadas por esses agentes, visando promover a produção, a distribuição e o uso da cultura, a preservação e divulgação do patrimônio histórico e o ordenamento do aparelho burocrático por elas responsável. Essas intervenções assumem a forma de:

1. normas jurídicas, no caso do Estado, ou procedimentos tipificados, em relação aos demais agentes, que regem as relações entre os diversos sujeitos e objetos culturais; e 2. intervenções diretas de ação cultural no processo cultural propriamente dito (construção de centros de cultura, apoio a manifestações culturais específicas, etc.). Como ciência da organização das estruturas culturais, a política cultural tem por objetivo o estudo dos diferentes modos de proposição e agenciamento dessas iniciativas bem como a compreensão de suas significações nos diferentes contextos sociais em que se apresentam. (Coelho, 1999:292)

Dentre os meios apropriados para que as políticas culturais sejam planejadas e executadas a contento - estas aplicadas ao interesse de iniciativas e projetos em história pública, história local e história oral (como qualquer outra iniciativa de matiz cultural) -, conforme acima esboçado, e mediante posturas favoráveis ao exercício de cidadania, é necessário que sempre haja a criação de vínculos formais entre as partes envolvidas. Uma dentre tantas definições possíveis acerca do termo cidadania seria de que esta "é um status que medeia a relação entre o indivíduo e a comunidade política. [A noção de] cidadania também fornece uma estrutura para as interaçoes entre os individuos dentro da sociedade civil' (Faulks, 2000: 107). Associações, sociedades e entidades civis com ou sem fins lucrativos; centros culturais, centros de memória, museus e arquivos, públicos e/ou privados, dependem de sua adequação a normas jurídicas que os permitam buscar financiamento para seu ordenamento burocrático e folha de pagamento, bem como para promover e contemplar o desenvolvimento de suas representações simbólicas.

Uma parceria entre, por exemplo, associações, sociedades ou grupos de pesquisadores em história pública, história local e história oral - ainda que genericamente denominadas por consultorias (porque os afazeres extrapolam a própria consultoria em pesquisa histórica) - e sociedades de amigos de bairro, representantes de comunidades locais, pode gerar frutos dos quais ambas as partes têm a responsabilidade pela sua colheita e consumo, porque emanadas destas autoridades compartilhadas previamente negociadas e, pari passu, amadurecidas. No caso de pesquisadores que representem o poder público, suas responsabilidades são igualmente correlatas a destes que integrem associações, sociedades ou grupos de pesquisa - uma vez que todos devam estar por demais atentos aos preceitos legais de transparência pública vigorantes em sociedades pautadas pelo estado democrático de direito, bem como pelo respeito aos direitos morais e patrimoniais de seus colaboradores em suas pesquisas e produções socioculturais.

Mesclar estes três campos do conhecimento histórico, contudo, é terreno pantanoso. Não raro, encontram-se diversas publicações, projetos e programas que inter-relacionam tais campos - empregando-os como bistória oral e pública; história pública e local; história oral e local. Mas é difícil encontrar alguma experiência que se autodenomine bistória pública, local e oral, concomitantemente. Aliás, o mais importante é que as iniciativas, procedimentos e resultados sejam contemplados de acordo com o esperado por pesquisadores, produtores culturais e comunidades beneficiárias, e público interessado. Várias experiências bem sucedidas podem ser enumeradas e descritas, desde o âmbito global ao regional/local, como as associações e sociedades históricas (a maioria das quais localizadas em países anglo-saxônicos) como a Oral History Association, Australian Historical Association e a British Association for Local History; os eventos socioculturais como os festivali di storia que se espalham pela Itália; em cursos de extensão ministrados em instituições acadêmicas abertas ao grande público como a Freie Universität de Berlim; de empresas de consultoria em organização de acervo e produção documental para grupos corporativos, como a brasileira Tempo e Memória (empresa privada esta inserida em um nicho de mercado em expansão no país, proporcionado pelo fortalecimento das políticas públicas de fomento e apoio à produção cultural); instituições acadêmicas como o Centro de Memória da Unicamp - idealizado pelo Prof. Dr. José Roberto do Amaral Lapa (1929-2000), historiador local campineiro, junto a outros pesquisadores e docentes do antigo Grupo de Estudos Regionais (GER) do Instituto de Filosofia e Ciências Humanas (IFCH-Unicamp) - que se dedica a promover, desenvolver e assessorar projetos e pesquisas em histórias local/regional referentes à Região Metropolitana de Campinas (RMC), Estado de São Paulo, em suas múltiplas possibilidades, inclusive por meio de história oral; e entidades privadas sem fins lucrativos, como a Fundação Pró-Memória de Sumaré, coordenada pelos historiadores locais Francisco Antonio de Toledo e Alaerte Menuzzo (exemplar associação que dá conta de produção documental, arquivística e sociocultural acerca do município e da gente nativa e/ou residente no município de Sumaré, Estado de São Paulo). 
À luz de diversas experiências em que foram inter-relacionados conceitos e práticas provenientes de história pública, história local e história oral, o "Centro de Memória de Hortolândia - Prof. Leovigildo Duarte Júnior", nos últimos dois anos, vem se envolvendo paulatinamente com a população munícipe a fim de "recuperar seu tempo perdido" e recuperar e ampliar seu acervo documental; organizar e digitalizar os fundos e coleções preexistentes compreendidos em seu acervo; e, sobretudo, desenvolver projetos, pesquisas e ações socioculturais em parceria a comunidades/ grupos detentores/produtores de bens/referências da cultura e memória local/regional, como forma de salvaguarda de seu patrimônio cultural, sobretudo, imaterial. Diz-se "recuperar seu tempo perdido" quando se trata do "Centro de Memória de Hortolândia", pois este é um órgão público vinculado à Prefeitura Municipal de Hortolândia, criado pela Lei Municipal 225/1994, o qual, até os últimos dois anos, não passara de letra morta, e cujo incipiente acervo constituído de fundo documental público remanescente das primeiras três gestões municipais - estivera abandonado em um cômodo subsolo de uma conhecida praça pública local - a Praça "A Poderosa". Para o momento, apenas vale dizer que a situação infraestrutural para a preservação do referido acervo se agravara a partir da morte de seu idealizador, professor Leovigildo Duarte Júnior (1941-2009), o qual já havia realizado trabalho análogo à vizinha Sumaré, contribuindo para a criação do referido "Pró-Memória". Em sua homenagem, o Centro de Memória de Hortolândia recebera recentemente seu nome, mediante a lei municipal 2.793/2013 - passando a se chamar "Centro de Memória de Hortolândia - Prof. Leovigildo Duarte Júnior".

Graças ao empenho de um grupo de técnicos lotados à jovem Secretaria Municipal de Cultura - inicialmente vinculada à Secretaria de Educação, posteriormente desmembrada desta juntamente com a pasta de Esporte, até adquirir plena autonomia administrativa, em 2011 -, o acervo remanescente sob custódia do "Centro de Memória de Hortolândia - Prof. Leovigildo Duarte Júnior” fora, literalmente, resgatado do referido antro - o qual passa, atualmente, por uma ampla reforma - e depositado, temporariamente, em um cômodo mais apropriado, localizado no Ponto de Cultura "Caixa de Luzes", até ser transferido para seu "destino final": a Estação Ferroviária Jacuba, único patrimônio cultural edificado tombado pelo município de Hortolândia, o qual também passa por uma ampla reforma/restauro/readequação, para receber as futuras instalações do "Centro de Memória de Hortolândia - Prof. Leovigildo Duarte Júnior".

Mas o caminho à plena estruturação física e à adequada organização de expedientes técnico e administrativo pelos quais vem passando o "Centro de Memória de Hortolândia - Prof. Leovigildo Duarte Júnior” não é curto. Para suprir esta demanda, propostas de projeto elaboradas com a finalidade de aquisição de equipamentos e mobiliários, além da organização e digitalização do acervo documental preexistente, aguardam a liberação de recursos públicos (incluindo recursos provenientes de deduções e incentivos fiscais), para que, de fato, o "Centro de Memória de Hortolândia - Prof. Leovigildo Duarte Júnior" "recupere seu tempo perdido". Por outro lado, o referido órgão público já deu início à elaboração de projetos de pesquisa e ações culturais que promovem a memória e a história locais, de modo que, já se percebe, autorias e responsabilidades são compartilhadas entre poder público, sociedade civil e comunidades interessadas na construção - do grau zero - de repertórios de ação coletiva em história pública, oral e local.

Desde finais de 2011, quando o presente autor apresentara à Secretaria Municipal de Cultura - da qual é agente cultural concursado - um projeto de pesquisa intitulado "Memória em Construção: Hortolândia e sua Gente em Narrativas e Imagens" - com a colaboração do também agente cultural concursado Anderson Zotesso Rodrigues, jornalista e mestre em semiótica pela Pontifícia Universidade Católica de São Paulo (PUC-SP), responsável pela produção fotográfica do referido projeto - o "Centro de Memória de Hortolândia - Prof. Leovigildo Duarte Júnior" busca ampliar seu acervo documental, por meio de produção emanada de conceitos e práticas em história oral, sobretudo aquelas que valorizam histórias de vida, objetos biográficos e lugares de memória, e a partir das quais entrevistados são entendidos como colaboradores - e não depoentes ou informantes - do referido projeto em execução.

O projeto "Memória em Construção", que busca se tornar um programa sociocultural - à medida que haja sua continuidade, por meio de ampliação da equipe técnica do "Centro de Memória de Hortolândia - Prof. Leovigildo Duarte Júnior” e, principalmente, interesse público em colaborar com a pesquisa e produção documental - é, sobremaneira, fundamentado em aportes conceituais e procedimentos metodológicos desenvolvidos por pesquisadores do Núcleo de Estudos em História Oral da USP (NEHO-USP), coordenado por José Carlos Sebe Bom Meihy, um dos pioneiros da história oral no Brasil. Por mais que o campo epistemológico desenvolvido dentro do NEHO-USP seja variado, e faça também da história oral um campo de militância política e ética, a elucidação de conceitos como estes acima referidos, bem como outros aptos a debater situações socialmente complexas como memória e identidade, oralidade e cultura escrita, tempo do tempo presente, narrativa, redes de colaboradores, dentre outros (Meihy e Ribeiro, 2011; Lopes, 2011; 
Artigos

Meihy e Holanda, 2011; Lopes, 2011, 2007), para os afazeres próprios do dia-a-dia no “Centro de Memória de Hortolândia - Prof. Leovigildo Duarte Júnior”, todos estes conceitos são inteiramente aplicáveis, ainda que seja necessário ao pesquisador não sobrepor questões teóricas e de método acima dos próprios temas públicos e locais.

Neste sentido, esta história oral referenciada pelo crescente arcabouço epistemológico desenvolvido por pesquisadores do NEHO-USP contribuiu para que o projeto "Memória em Construção" também se tornasse um projeto em história pública e em história local, pois seus colaboradores se comportam e se responsabilizam pelo conteúdo de suas narrativas confiadas ao "Centro de Memória de Hortolândia - Prof. Leovigildo Duarte Júnior”, portando-se, inclusive, como historiadores públicos (no sentido de memorialistas e documentalistas locais), principalmente pelo fato de que uma história local digna de sua gente - isto é, desapegada de interesses políticos e escusos - ainda está por ser escrita. No presente momento, sem estas pessoas, como muitas outras que merecem e precisam ser ouvidas, o referido trabalho seria impossivel de ser desenvolvida.

Para sua primeira fase, foram recentemente concluídos os procedimentos técnicos em história oral (gravação, transcrição/transcriação, autorização de uso público) sobre 10 entrevistas, as quais foram realizadas com a colaboração de 6 homens e 4 mulheres, das mais diversas profissões e origens (dentre migrantes e nativos). As fotografias produzidas por Anderson Zotesso também estão recebendo processamento técnico arquivístico, mas podem - bem como a documentação em história oral - ser acessadas mediante solicitação simples junto ao "Centro de Memória de Hortolândia - Prof. Leovigildo Duarte Júnior". Para a devolução pública, está em conclusão uma produção bibliográfica na qual é seja criado um diálogo historiográfico entre as documentações ditas tradicionais (inclusive, inéditas) e esta produzida a partir do projeto original "Memória em Construção"; e cuja distribuição de exemplares físicos será gratuita e destinada a instituições de ensino e pesquisa locais e regionais, bem como a cidadãos interessados em adquiri-lo. O financiamento para a referida produção cultural bibliográfica está autorizado para exercício de 2014, mediante dedução ou incentivo fiscais (PRONAC, Lei Federal 8313/91). Espera-se, entretanto, que o projeto não se esgote com uma primeira a devolução pública bibliográfica, que se torne um programa e continue a contribuir para a ampliação do acervo do "Centro de Memória de Hortolândia - Prof. Leovigildo Duarte Júnior", e, principalmente, estimule hortolandenses serem cada vez mais responsáveis pela vivacidade de suas histórias de vida, de seu município e de amplos e/ou específicos temas socioculturais pertinentes à realidade local.

Outra recente atribuição do "Centro de Memória de Hortolândia - Prof. Leovigildo Duarte Júnior", que não fora contemplada no diploma legal de sua criação é a promoção do patrimônio cultural material e imaterial local. Paralelamente a este projeto, o "Centro de Memória de Hortolândia - Prof. Leovigildo Duarte Júnior", juntamente à equipe técnica da Secretaria Municipal de Cultura, e em parceira com os grupos detentores/produtores da cultura caipira obtiveram uma importante conquista para a tessitura de laços identitários locais/regionais: a $2^{a}$ colocação do projeto "Patrimônios Vivos da Cultura Caipira em Hortolândia: Mestres Violeiros, Foliões e Catireiros" em edital promovido pelo Programa Nacional do Patrimônio Imaterial do Instituto do Patrimônio Histórico Artístico Nacional - Edital n ${ }^{\circ} 1$ PNPI-IPHAN 2012 (Convênio no774932/2012).

Por meio desta conquista, fora celebrado convênio entre Prefeitura Municipal de Hortolândia e IPHAN com objetivo de: promover o reconhecimento público de mestres e grupos da cultura caipira local; criar oficinas culturais de introdução teórica e prática à viola e à dança do catira, ministradas, respectivamente, por mestres violeiros e catireiros; realizar oficinas de educação patrimonial ministradas por técnicos da Secretaria Municipal de Cultura e do "Centro de Memória de Hortolândia - Prof. Leovigildo Duarte Júnior”, acompanhados de mestres da cultura caipira local; desenvolver pesquisas e produção documental (do qual a história oral é procedimento-chave) acerca de conceitos e experiências em gestão do patrimônio cultural imaterial e, especialmente, sobre passado e presença da cultura caipira em Hortolândia e regiões brasileiras; organização do I Seminário sobre Patrimônio Cultural Imaterial de Hortolândia; e produção do CD-Libreto que apresente resultados práticos das oficinas de viola e dança do catira, e das pesquisas desenvolvidas ao longo do projeto, a ser executado em 1 ano com vistas ao aditamento do convênio por igual período.

Singelo fruto da própria trajetória político-administrativa, econômica e sociocultural do município de Hortolândia, este incipiente repertório de ação coletiva em histórias pública, oral e local pode contribuir para o fortalecimento dos debates que envolvem questões de memória e identidade. É ação coletiva formada por gente de grupos/comunidades, que entende, faz, vive cultura; por gestores vinculados ou a serviço de órgãos/entidades culturais, públicas e privadas, em suas mais variadas atribuições; por pesquisadores e educadores acadêmicos, profissionais e amadores/voluntários igualmente interessados no fortalecimento de memórias e identidades locais e regionais, por meio de produção inte- 
lectual e documental acessível, sobretudo, ao uso da população munícipe; e por tantos outros colaboradores(as) diretos e indiretos, nativos e residentes, ou não, em Hortolândia. No passo de históricas manifestações e reivindicações populares substanciais ocorridas e vivenciadas em Hortolândia - como a pela emancipação política/administrativa e pela implantação de tudo que é necessário para um município, ou qualquer localidade, sobreviver - este repertório e ação coletiva cultural igualmente emana do interesse público pela identificação, manutenção, e transmissão de saberes e fazeres que permeiam memórias e identidades locais e regionais (Lopes, 2012a, 2012b).

É premente, em especial, a promoção do saber histórico sobre este antigo bairro rural caipira, paulista, campinense, denominado "Jacuba", que se tornara um município populoso; eficiente arrecadador tributário; polo industrial atraente a investimentos externos; e local que ainda vivencia grandes contrastes sociais (IBGE, 2010). Hortolândia é um município fundado a 31 de dezembro de 1991, mas que comemora sua emancipação a cada 19 de maio - efeméride da realização do plebiscito que decidira seu futuro político-administrativo, amplamente favorável ao desmembramento do então distrito em relação município de Sumaré (a realização e legitimidade do plebiscito, amparado pela Constituição de 1988, vale lembrar, fora conquistado mediante intensa manifestação pública). Sua população atual, distribuída em 62,2 Km2, é estimada em cerca de 200 mil habitantes; diferentemente de seus 1.000 habitantes à época em que fora elevada a distrito de Sumaré, a 30 de dezembro de 1953. É um município que merece maior atenção de especialistas para compreender o que ocorreu à localidade, ao menos, nos últimos 60 anos. Percebe-se, pois, evidentes melhorias de Hortolândia, bem como de toda a Região Metropolitana de Campinas, se comparados atuais dados socioeconômicos aos publicados nos últimos dez anos (Cano e Brandão, 2002).

As políticas públicas culturais, por sua vez, também têm sua parcela de contribuição nesse atual quadro de aparentes melhorias, à medida que representantes do poder público municipal e da sociedade civil vem compartilhando responsabilidades na gestão de bens/referências culturais, bem como na construção e fortalecimento do Conselho Municipal de Cultura, do Fundo Municipal de Cultura, do Sistema Municipal de Cultural, do Plano Municipal de Cultura, e do Sistema Municipal de Informações e Indicadores Culturais - recentemente sancionados pelas Leis Municipais 2.693/2012, 2.769/2013, 2.785/2013 e 2.830/2013, respectivamente. Nos dias de hoje, a população hortolandense - nativa e/ou migrante, em especial aquela que ainda se organiza sociocomunitariamente - não se manifesta ou reivindica apenas a garantia de exercício dos direitos sociais mais básicos, mas também do direito à cultura, em suas mais diversas representações simbólicas; inclusive, a do direito à memória e de transmissão de saberes e fazeres identitários. Políticas culturais, que incorporam e promovem iniciativas e projetos em história pública e correlatos, podem tecer meios que garantam o exercício de cidadania em comunidades locais, desde que fiadas com real anuência e elaboradas com vistas à geração de benefícios econômicos e socioculturais. É necessário que as partes envolvidas nessas políticas públicas culturais compartilhem autoridades e autorias na construção dos diversos repertórios de ação coletiva para que não caiam por terra iniciativas e projetos como estes acima elencados. Para tanto, procedimentos e práticas em bistórias pública, oral e local estão à disposição.

\section{Referências bibliográficas}

ALMEIDA, Juniele Rabêlo de; ROVAI, Martha Gouveia de Oliveira (org.). 2011. Introdução à História Pública. São Paulo, Letras e Voz, 416 p.

ASSIS Amit. 2011. Author-Ity. In: Mafte'akh - Lexical Review of Political Thought. Tel Aviv, Minerva Humanities Center. Inverno. pp.1-28.

BAUMAN, Zigmunt. 2003. Comunidade: a busca por segurança no mundo atual. Rio de Janeiro, Jorge Zahar, 141p. 1999. Ensaios sobre o Conceito de Cultura. Rio de Janeiro, Jorge Zahar, 328p.

CANO, Wilson; BRANDÃO, Carlos Rodrigues. 2002. A Região Metropolitana de Campinas: urbanização, economia, finanças e meio ambiente - 2 volumes. Campinas, Editora da Unicamp, 916p.

CAUNCE, Stephen. 1994. Oral history and the local historian. Londres e Nova Iorque, Longman, 227p.

HAYDEN, Dolores. 1997. The Power of Place: Urban Landscapes as Public History. Cambrige, MIT Press, 296p.

HAMILTON, Paula; SHOPES (ed.). 2008. Oral Histories and Public Memories. Filadélfia, Temple University Press, 320p.

KELLEY, Robert. 1978. Public History, Nature and Prospects. In: The Public Historian sv.1, n.1, Outono, p.16. FAULKS, Keith. 2000. Citizenship. Londres e Nova Iorque, Routledge, 190p. 
Artigos

FRISCH, Michael. 1990. A shared authority : essays on the craft and meaning of oral and public history. Albany, State University of New York, 273p. . 2011. From a Shared Authoruty to the Digital Kitchen, and Back. AIDAR, B.; FILENE, B.; KOLOSKI, L (ed.). In: Letting go? Sharing historical Authority in a User-Generated World. Filadélfia, Pew Center for Arts and Heritage, pp. 128-37.

KAMMEN, Carol. 2003. On Doing Local History. Walnut Creek, Altamira. 189p.

LOPES, Gustavo Esteves. 2012. Dança do Catira: Bem da Cultura Caipira Local e Regional In: Revista Típica Regional. Sumaré/Hortolândia: Seta Regional, ano VI, n.23, pp.22-3.

. 2012. Estação Ferroviária Jacuba: Patrimônio Cultural Municipal de Hortolândia. In: Revista Típica Regional. Sumaré/Hortolândia: Seta Regional, ano V, n20, pp.36-9.

. A atualização do NEHO nos últimos anos. In: Oralidades - Revista de História Oral. São Paulo: NEHO, n.1, jan-jun, pp.77-85.

MEIHY, José Carlos Sebe Bom; HOLANDA, Fabíola. História Oral: Como Fazer, Como Pensar. São Paulo, Contexto, $175 \mathrm{p}$.

MEIHY, José Carlos Sebe Bom; RIBEIRO, Suzana Lopes Salgado. 2011. Guia Prático de História Oral: para empresas, universidades, comunidades, famílias. São Paulo, Contexto, 208p.

TEIXEIRA, Coelho. 1999. Dicionário Crítico de Politica Cultural: Cultura e Imaginário. São Paulo, Iluminuras, $383 \mathrm{p}$.

TILLY, Charles. 1995. Contentions Repertoires in Great Britain, 1758-1834. In: TRAUGOTT, Mark (ed.). Repertoires and Cycles of Collective Action. Durham, Duke University Press, pp. 15-42. 